\title{
Vitellogenin assay by enzyme-linked immunosorbant assay as a biomarker of endocrine disruptor chemicals pollution
}

\begin{abstract}
There is increasing evidence that many xenobiotic chemicals (called as endocrine disruptor chemicals, EDCs) through interfering with the endocrine system, have the capability to induce developmental and reproductive abnormalities in humans and animals. The yolk protein precursor vitellogenin $(\mathrm{Vtg})$ has proved to be a simple and sensitive biomarker for assessing exposure of fish to EDCs, especially the estrogenic compounds. Work is ongoing to develop screening and testing programmes for endocrine disrupting effects of new chemicals, and in the focus of this development are the fish test species common carp (Cyprinus carpio). In this study, we have developed quantitative enzyme-linked immunosorbent assays (ELISA) for VTS in common carp. The working range of the ELISA was $11.25-2000 \mathrm{ng} / \mathrm{ml}(75-25 \%$ specific binding/maximum antibody binding $[\mathrm{B} / \mathrm{B} 0]$ ) with a $50 \% \mathrm{~B} / \mathrm{B} 0$ intra and interassay variation of $3.9 \%(n=10)$ and $12.5 \%(n=30)$, respectively. This ELISA is capable of detecting Vtg as low as $6 \mathrm{ng} / \mathrm{ml}$, and can accurately detect Vtg in even $10 \mathrm{ml}$ of plasma. The ELISA was applied to measurement of Vtg production by male carp (C. carpio, Cyprinidae) fish exposure to ethynylestradiol. The results showed that the amount of Vtg produced in plasma of exposed fish increased in logarithmic order comparing to the control group and the ELISA described here could be used as an indicator of water pollution to estrogenic pollutants.
\end{abstract}

Key words: ELISA, Endocrine disruptor chemicals, Immunoassay, Vitellogenin

\section{INTRODUCTION}

The last two decades have witnessed growing scientific concerns and public debate over the potential adverse effects that may result from exposure to a group of chemicals that have the potential to alter the normal functioning of the endocrine system in wildlife and humans. ${ }^{[1]}$ According to WHO definition, an endocrine disruptor chemical (EDC) is an exogenous substance or mixture that alters function(s) of the endocrine system and consequently causes adverse health effects in an intact organism, or its progeny or (sub) populations. The EDCs encompass a variety of chemical classes, including natural and synthetic hormones, plant constituents, pesticides, compounds used in the plastics industry and in consumer products, and other industrial by-products and pollutants. ${ }^{[2]}$

Mammalian studies have focused on the male since it is much easier to determine changes in the quality and quantity of sperm than of eggs, because eggs are few and are retained internally. ${ }^{[3]}$ Fish have a major advantage over mammals in studies of endocrine disruptors in that they produce large numbers of both eggs and sperms and release them to the external environment. Hence, the effects of potential endocrine disruptors can be readily examined in both sexes. An assessment of pollution requires a simple biomarker and Vtg can be the easiest choice.

In very simple terms, vitellogenesis involves ovarian estradiol stimulating the liver to produce Vtg, which in turn is incorporated into the yolk of developing oocytes. Estrogenic xenobiotics can also act on the hepatic receptors to induce synthesis of Vtg. ${ }^{[4]}$ Both male and female fish, as well as immature juveniles have hepatic estrogen receptors, but only the livers of female fish will normally be exposed to estrogens. ${ }^{[5]}$ Production of Vtg by males and juveniles, or nonvitellogenic females can therefore provide a bioindicator of exposure to environmental estrogens. ${ }^{[6]}$

A number of studies have used Vtg to
M. Ebrahimi Environmental Hormones Pollutants Research Center, University of Qom, Qom, Iran

For correspondence: Dr. M. Ebrahimi, Environmental

Hormones Pollutants Research Center, University of QOM, QOM, Iran. E-mail: ebrahimi@qom.ac.ir

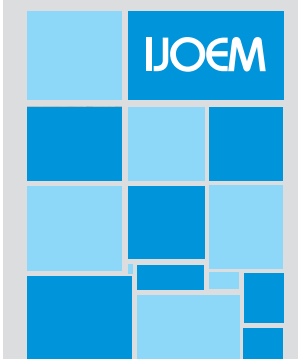


demonstrate the presence of estrogenic chemicals in the aquatic ecosystem. Trout exposed to sewage effluent in English rivers had up to 100 000-fold increase in plasma Vtg compared to fish upstream of the effluent. ${ }^{[7]} \mathrm{A}$ follow-up study in which caged trout were held in the River Aire, which is polluted by detergents from textile mills, showed Vtg levels of more than $20 \mathrm{mg} / \mathrm{ml} 5 \mathrm{~km}$ downstream of the effluent. ${ }^{[8]}$ Elevated plasma Vtg was also found in eels below the Paris outfall. ${ }^{[9]}$ Because eels may spend up to 20 years in the river before their spawning, migration-consequent reproductive disruption may account for some of the decrease in the European eel population. ${ }^{[9]}$ The flounder, as a bottom-dwelling estuarine species, also provides a useful biomonitor of effluents in the rivers, which may potentially affect marine fish stocks. ${ }^{[10]}$ In another study, male flounder in a number of British rivers had elevated plasma Vtg and, in the River Mersey, the concentrations were around $100 \mathrm{mg} / \mathrm{ml}$ (ten million times higher than controls). ${ }^{[1]}$

During the last 15 years, there have been a number of publications in which enzyme-linked immunosorbent assay (ELISA) using microtiter plates have been described as an alternative to radioimmunoassay for the mammalian and nonmammalian assays. ${ }^{[12]}$ In addition to interest in measurement of steroids in fish plasma as an aid to aquaculture, there is increasing interest in such measurements to monitor the effects of endocrine disrupting chemicals on their reproductive function. ${ }^{[13]} \mathrm{A}$ repor ${ }^{[14]}$ has highlighted the need for a simple, rapid, and reliable method for the measurement of hormones specific to fish and other nonmammalian vertebrates as the basis for regulatory testing of the effects of potential endocrine disrupters on wildlife. In this communication, we describe a general preparation procedure for the enzyme label of carp Vtg, which is applicable to other species. The method was applied to the determination of Vtg production by ethynylestradiol, a potent xenoestrogen, in Carp (Cyprinus carpio) plasma.

\section{MATERIALS AND METHODS}

\section{Chemicals and equipment}

The C. carpio Vtg and anti-Vtg antibodies were kind gifts from Professor Oliana Carnevali, Dipartimento di Biologia MCA, University of Camerino, 62032 Camerino, Italy. The purified Vtg is diluted to 10 and $50 \mathrm{mg} / \mathrm{ml}$ with Vtg storage buffer [PPBS, $0.1 \mathrm{M}, \mathrm{pH} 7.4$; Potassium chloride, $27 \mathrm{mM}_{i}$ Tween-20, $0.05 \%$; Bovine Serum Albumin, $0.2 \%$; Sodium Azide, $5 \mathrm{mM}_{i}$ Aprotinin, $20 \mathrm{TIU} / \mathrm{ml}$, 1\% (Sigma, Deisenhofen, Germany)], divided into various volumes in eppendorf tubes and stored at $-20^{\circ} \mathrm{C}$. Goat $\mathrm{F}\left(\mathrm{ab}^{\prime}\right) 2$ fragment of affinity isolated rabbit antigen-specific antibody, conjugated to alkaline phosphatase was obtained from Sigma Immuno Chemicals (catalogue number A-3937). 4-Nitrophenylphosphate (pNPP) obtained from Boehringer Mannheim GmbH (catalogue number 107 905).

Ninety-six well polystyrene high-binding microtiter plates (Costar catalogue number 3590) were used for the ELISA. Plates were sealed for storage with Anachem Sealplate sealing film. Plates were processed using a Chelsea Instruments shaker, an Anthos Model AW-1 plate washer and read with an Anthos Model HTII Plate Reader. Ninety-six well low-binding microtiter plates (Costar catalogue number 2501) were used for sample dilution and preparation of standard curves and AnachemÒ SEALPLATE plate sealing film, (PK/100) purchased from Anachem (United Kingdom).

\section{Fish exposure}

Four groups of six male common carp (initial mean weight: $268.9 \pm 52.5 \mathrm{~g}$, mean \pm SD) originating from a local fish breeder farm (Mahyar company, Iran) were kept in four separate tanks. They were exposed to $0,5,10$, and $50 \mathrm{ng} / \mathrm{ml}$ ethynylestradiol for 30 days. Blood samples were taken at 0 , 10,20 , and 30 days of exposure and plasma kept at $-20^{\circ} \mathrm{C}$ until Vtg assay.

\section{Plate coating with Vtg}

ELISA plates were coated with $50 \mathrm{ng}$ of purified Vtg. About $100 \mathrm{ml}$ of carbonate buffer $(0.05 \mathrm{M}, \mathrm{pH} 9.6)$ containing $500 \mathrm{ng} / \mathrm{ml}$ of purified standard Vtg added to each well of the plate and incubated for $1 \mathrm{~h}$ at room temperature in a humid container and then overnight at $4^{\circ} \mathrm{C}$ and washed once with nanopure water. The plate was blocked by the addition of a $200 \mathrm{ml}$ per well of fresh Vtg blocking buffer [potassium phosphate buffer (PPB) $0.1 \mathrm{M}, \mathrm{pH} 7.4$; bovine serum albumin, $2 \%$; sodium azide, $5 \mathrm{mM}$ ], washed three times with wash buffer [Potassium phosphate buffered saline (PPBS), $0.02 \mathrm{M}$, $\mathrm{pH} 7.4$; Tween-20, 0.05\%] sealed with plate cover and stored at $-20^{\circ} \mathrm{C}$.

\section{Standard assay procedure}

Serial dilutions of purified standard Vtg $(2000-3.9 \mathrm{ng} / \mathrm{ml})$ in $100 \mathrm{ml} \mathrm{Vtg}$ assay buffer were made in the first ten wells of rows $A$ and $B$ of the coated plate. The remaining two wells in these rows were reserved for B0 (0pg) and nonspecific bound (NSB). Ten microliters of the diluted samples from sample dilution plate $(2,200$, and 2000 times) was pipetted into the remaining six rows in duplicate. Twenty microliters of antiVtg antisera diluted 1/15 000 (carp) in Vtg assay buffer was added to all wells apart from NSB wells and made up the wells to $150 \mathrm{ml}$ by Vtg assay buffer. The plates were sealed and incubated $2 \mathrm{~h}$ at room temperature in a humid chamber. Plates were then washed three times with wash buffer and $150 \mathrm{ml}$ of anti-rabbit IgG alkaline phosphatase conjugate diluted 1/15 000 in Vtg assay buffer added to each well and incubated overnight at $4^{\circ} \mathrm{C}$ temperature. Plate was washed 
with wash buffer once and then twice with pNPP Substrate buffer (diethanolamine, 0.5 M, pH 9.8; $\mathrm{MgCl}, 0.5 \mathrm{mM}$ ), $175 \mathrm{ml} /$ well of $1 \mathrm{mg} / \mathrm{ml}$ 4-nitrophenylphosphate in pNPP Substrate buffer added and then incubated in dark at room temperature until color developed to around 1.5 ODs (normally approximately $45 \mathrm{~min}$ but can be left up to $4 \mathrm{~h}$ ). The reaction stopped by adding $50 \mathrm{ml}$ of $3 \mathrm{M} \mathrm{NaOH}$ and read at $405 \mathrm{~nm}$. Nanograms per ml were calculated for the samples from the standard curve using Stingray software (Dazdaq, Ringmer, UK).

\section{Assay validation}

A pool of male common carp (C. carpio) plasma (500 ml) was treated with $100^{\circ} \mathrm{C}$ for $1 \mathrm{~h}$ to remove all proteins from the plasma. One hundred microliter aliquots were pipetted in duplicate into wells on two rows of a microtiter plate. Pure Vtg was added to one pair of wells to give a concentration of $2000 \mathrm{ng} /$ well, serial dilutions (2x) performed and the samples assayed according to standard procedure. The same procedure was used to assay Vtg in by carp exposed to ethynylestradiol $(0,5,10$, and $50 \mathrm{ng} / \mathrm{ml})$. SPSS 10 for Windows software (SPSS Inc., 444 N. Michigan Avenue, Chicago, Illinois 60611, USA) was used for the statistical analysis of Vtg production in plasma of control fish group $(0 \mathrm{ng} / \mathrm{ml}$ ethynylestradiol) with other experimental groups $(5,10$, and $50 \mathrm{ng} / \mathrm{ml}$ ethynylestradiol).

\section{RESULTS}

\section{Standard curves and assay sensitivity}

Typical standard curves for Vtg showed the working range of the ELISA was 11.25 - $2000 \mathrm{ng} / \mathrm{ml}$ [Figure 1] [75 - 25\% specific binding/maximum antibody binding (B/B0)] with a 50\% B/B0 intra and interassay variation of $3.9 \%(n=10)$ [Figure 2] and
$12.5 \%(n=30)$, respectively. This ELISA is capable of detecting Vtg as low as $6 \mathrm{ng} / \mathrm{ml}$.

\section{Assay accuracy}

There was a strong positive correlation $(r>0.999)$ between the amount of Vtg added to deproteinated plasma and the amount found [Figure 3].

\section{Application to measuring Vtg production by carp exposed to ethynylestradiol}

The Vtg was measured in duplicate by ELISA using $10 \mathrm{ml}$ of the diluted plasma $(2 \mathrm{x}, 200 \mathrm{x}$, and 2000x) from fish exposed to different concentrations of ethynylestradiol. The amounts of Vtg detected by this method was 0, $402 \pm 50.6,6790 \pm 1235$, and $49824 \pm 10423 \mathrm{mg} / \mathrm{ml}$ (mean \pm standard error of mean, for six fish in each group) for fish exposed to $0,5,10$, and $50 \mathrm{ng} / \mathrm{ml}$ of ethynylestradiol for 30 days respectively [Figure 4]. A clear and potent estrogenic activity in inducing Vtg by fish liver was found with increase in ethynylestradiol concentration exposure and the amount of Vtg induced by different concentrations of ethynylestradiol between control $(0 \mathrm{ng} / \mathrm{ml})$ and experimental $(5,10$, and $50 \mathrm{ng} / \mathrm{ml})$ groups and between experiment groups were different significantly $(P<0.05)$.

\section{DISCUSSION}

Examination for the effects of potential EDCs begins only at levels at which there is no apparent stress or discomfort to the animal, so that it is potentially and equally able to reproduce. ${ }^{[15]}$ Reproductive dysfunction at such low concentrations can be caused either by direct action on the gametes, or indirectly by modulation of the endocrine system so that gamete development takes place during an imbalance in the hormonal environment. ${ }^{[16]}$

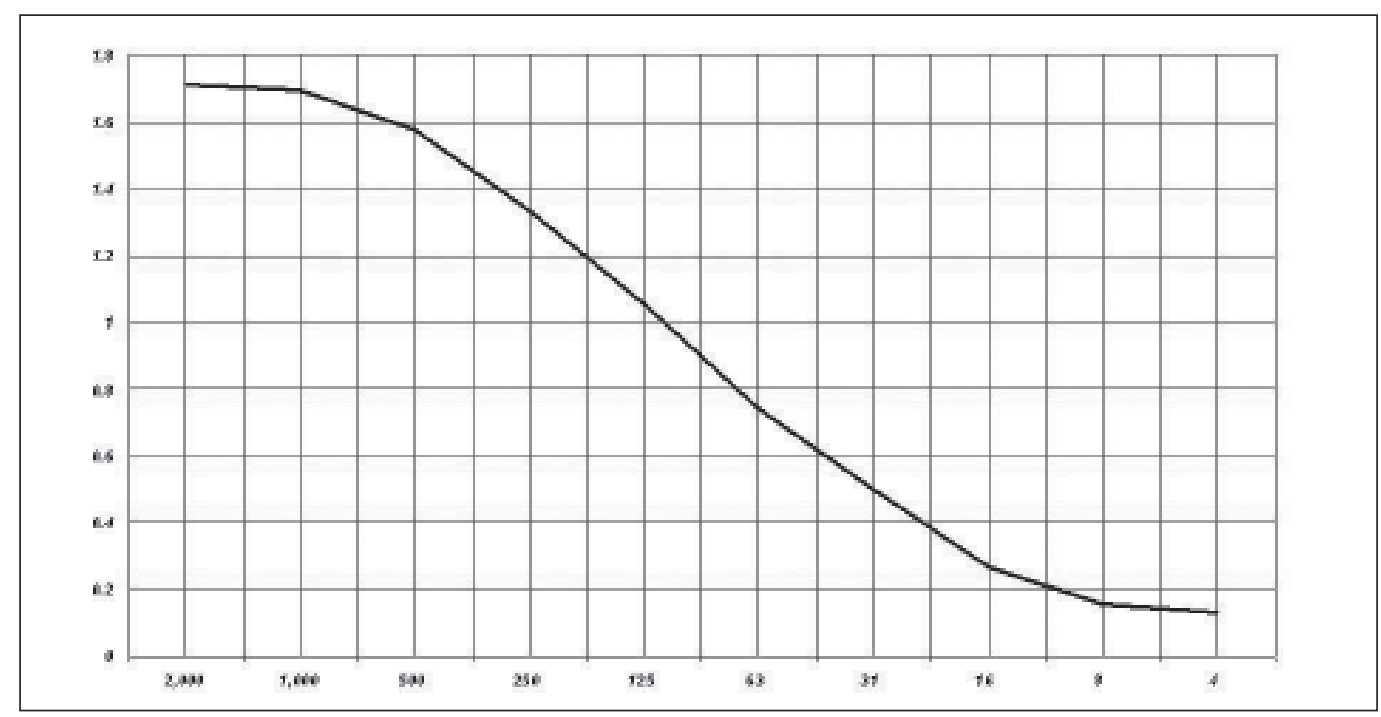

Figure 1: Typical standard curves for ELISA of 17, 20aP. Values are means of duplicate assays 


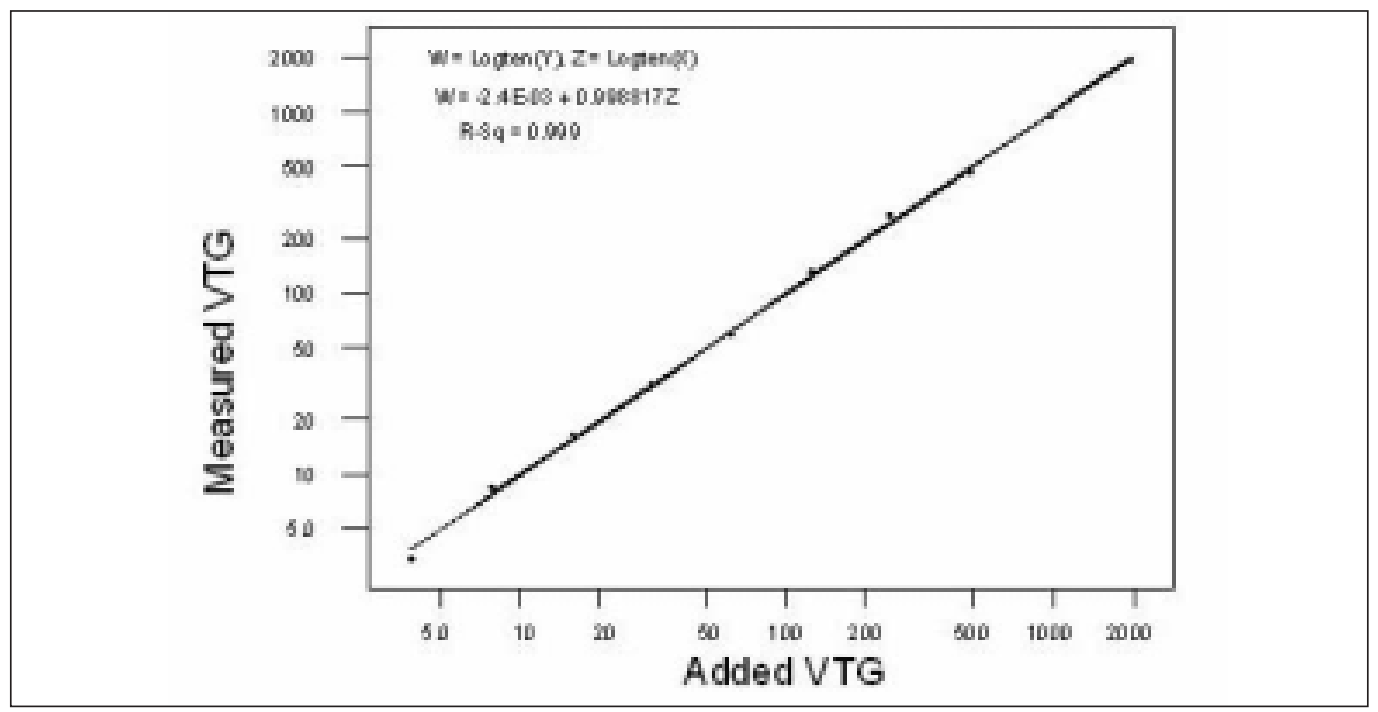

Figure 2: Intra-assay coefficient of variance (CV) for ELISA of vitellogenin (Vtg) determined from a standard curve with ten replicates at each concentration

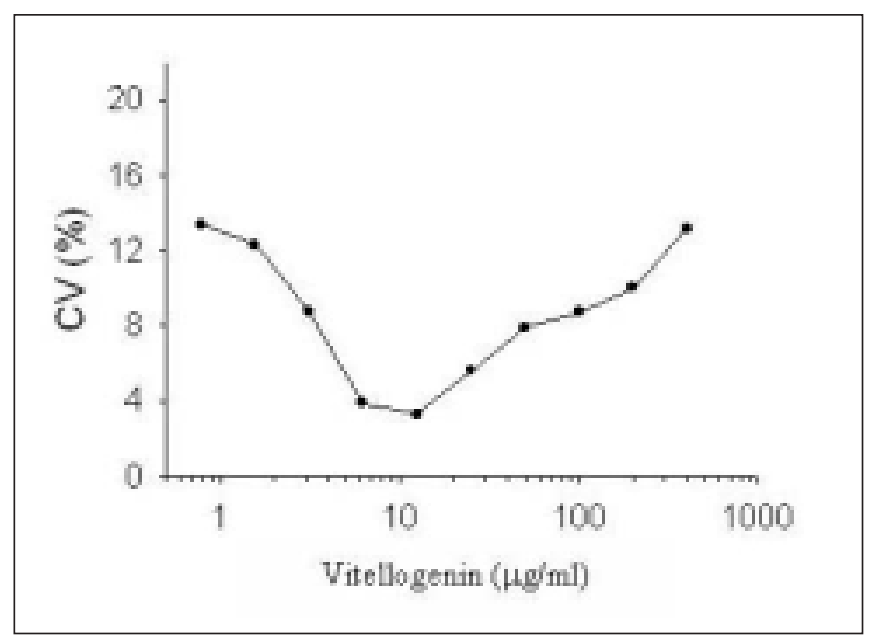

Figure 3: Assay accuracy for vitellogenin (Vtg) in deproteinized plasma. A known amount of $\mathrm{Vtg}$ was added to an aliquot of a protein-free carp plasma and $2 x$ serial dilutions made with it. Assays were performed in duplicate

In female fish, endocrine modulators can affect hypothalamic gonadotrophin releasing hormone (GnRH) secretion, pituitary gonadotrophin $(\mathrm{GtH})$ release, estrogen biosynthesis and catabolism, estrogen binding to hepatic receptors, hepatic Vtg production, or the feedback by steroids and Vtg. ${ }^{[17]}$ Although hepatic production of Vtg in male fish could be initiated by estrogens hormone, but no estrogenic hormones secrete in male fish and no Vtg production can be expected in normal life. ${ }^{[7]}$ The use of in vitro fish hepatocyte cultures or in vivo fish exposure to estrogenic chemicals is shown to provide a simple and effective way to screen estrogenic activities of EDCs. ${ }^{[18]}$ The Vtg assay in cell culture or fish plasma needs a quick, cheap, reliable, and efficient method to fulfill such a duty ${ }^{[19]}$ and many researchers have already introduced different techniques to measure Vtg. ${ }^{[20],[7]}$ An ELISA method for assaying Vtg has been described here.

\section{Assay validation}

Sensitivity: Sensitivity of the assays, which has been taken as $90 \%$ of the binding with 0pg is just over $10 \mathrm{mg}$ for Vtg. Using identical conditions for label preparation and assay we also obtained a sensitivity of $2 \mathrm{mg}$ for Vtg comparable to that obtained by others. ${ }^{[21]}$ As with radioimmunoassay, the sensitivity is a function of both the specific activity of the label and the quality of the antiserum, and will therefore vary with the material available to the user. So in this study, we used the antiserum that were available to us but have little reason to expect that any antiserum which gives good results with RIA will not give similar results to those that we describe for ELISA.

Previous reports of ELISA for Vtg have used different enzyme labels ${ }^{[22]}$ and in this communication a method described previously ${ }^{[23]}$ and the results showed it is sufficiently sensitive for the rapid measurement of Vtg in common fish species such as cyprinids, and an example of such an application was described.

Accuracy and reproducibility: A major advantage of ELISA is the ability to minimize errors resulting from multiple pipetting by use of multichannel pipettes. Inter and intraassay coefficient of variations (CV) reported in RIA are frequently $15-20 \%$ even when measured at the steepest part of the curve. For the assays reported here we obtain intraassay CVs around $3.9 \%$ in the steep part of the curve, rising to $15-20 \%$ at the flatter end regions [Figure 2], while interassay variation (at 50\% displacement) was around $12 \%$, comparable to that reported by Cuisset et al. ${ }^{[23]}$ for 11-ketotestosterone steroid hormone. There was a highly significant correlation between the Vtg added to and that measured in deproteinized carp plasma [Figure 3] and carp plasma. A further advantage 


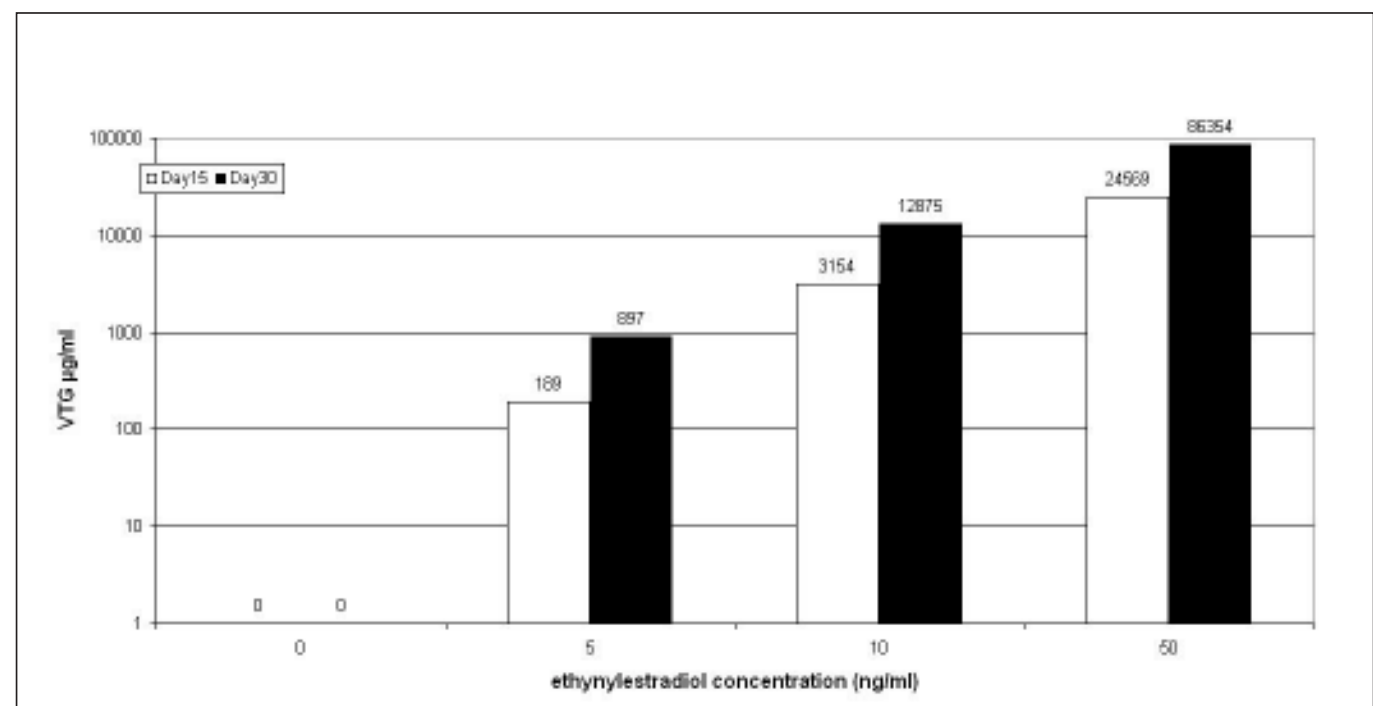

Figure 4: The amount of vitellogenin assayed in fish plasma exposed to different concentrations of ethynylestradiol for 30 days (vertical bars indicate SE and * means significant differences in Vtg induction)

of ELISA is that sample handling can also be made more rapid and reproducible by the use of low binding microtiter plates for sample storage and dispensing with multichannel pipettes

\section{Application to the measurement of Vtg production in fish}

To demonstrate an application of the ELISA method we have measured the amount of Vtg produced by carp exposed to ethynylestradiol. The results confirmed the previous findings that ethynylestradiol is a potent estrogenic chemical ${ }^{[24]}$ [Figure 4] and a clear, and potent estrogenic activity in inducing Vtg by fish was found with increase in ethynylestradiol concentration and the time of exposure (15 vs 30 days) [Figure 4]. The amounts of Vtg production in fish exposed increased dramatically so that the logarithmic scales were used to demonstrate it as shown in [Figure 4]. Such a potent induction of Vtg in other studies have already been discussed. ${ }^{[25]}$

The rapid determination of Vtg from the very small volumes of blood allows the examination of water pollution with EDCs and this methodology will therefore be of great interest to workers screening the estrogenic of new chemicals and phytoestrogens.

\section{REFERENCES}

1. Tsutsumi O. Effects of endocrine disruptors on preimplantation embryo development. Nippon Rinsho 2000;58:2464-8.

2. Damstra T, Barlow S, Bergman A, Kavlock S. Global assessment of the state of the science of endocrine disruptors. 2002;30-60.

3. Lathers CM. Endocrine disruptors: a new scientific role for clinical pharmacologists? Impact on human health, wildlife, and the environment. J Clin Pharmacol 2002;42:7-23.

4. Nakari T. Estrogenicity of municipal effluents assessed in vivo and in vitro. Environ Toxicol 2004;19:207-15.
5. Versonnen BJ, Janssen CR. Xenoestrogenic effects of ethinylestradiol in zebrafish (Danio rerio). Environ Toxicol 2004;19:198-206.

6. Hornung MW, Jensen KM, Korte JJ, Kahl MD, Durhan EJ, Denny JS, et al. Mechanistic basis for estrogenic effects in fathead minnow (Pimephales promelas) following exposure to the androgen 17alphamethyltestosterone: conversion of 17alpha-methyltestosterone to 17alpha-methylestradiol. Aquat Toxicol 2004;66:15-23.

7. Aerni HR, Kobler B, Rutishauser BV, Wettstein FE, Fischer R, Giger $\mathrm{W}$, et al. Combined biological and chemical assessment of estrogenic activities in wastewater treatment plant effluents. Anal Bioanal Chem 2004;378:688-96.

8. Sharpe RL, MacLatchy DL, Courtenay SC, Van Der Kraak GJ. Effects of a model androgen (methyl testosterone) and a model anti-androgen (cyproterone acetate) on reproductive endocrine endpoints in a shortterm adult mummichog (Fundulus heteroclitus) bioassay. Aquat Toxicol 2004;67:203-15.

9. Versonnen BJ, Goemans G, Belpaire C, Janssen CR. Vitellogenin content in European eel (Anguilla anguilla) in Flanders, Belgium. Environ Pollut 2004;128:363-71

10. Madsen LL, Korsgaard B, Bjerregaard P. Estrogenic effects in flounder Platichthys flesus orally exposed to 4-tert-octylphenol. Aquat Toxicol 2003;64:393-405.

11. George S, Gubbins M, MacIntosh A, Reynolds W, Sabine V, Scott A, et al. A comparison of pollutant biomarker responses with transcriptional responses in European flounders (Platicthys flesus) subjected to estuarine pollution. Mar Environ Res 2004;58:571-5.

12. Yamada H, Satoh R, Ogoh M, Takaji K, Fujimoto Y, Hakuba T, et al. Circadian changes in serum concentrations of steroids in Japanese char Salvelinus leucomaenis at the stage of final maturation. Zoolog Sci 2002;19:891-8.

13. Wade MG, Foster WG, Younglai EV, McMahon A, Leingartner K, Yagminas A, et al. Effects of subchronic exposure to a complex mixture of persistent contaminants in male rats: systemic, immune, and reproductive effects. Toxicol Sci 2002;67:131-43.

14. Tattersfield L, Matthiessen P, Campbell P, Grandy N, Lange R. SETACEurope/OECD/EC Expert Workshop on Endocrine Modulators and Wildlife: Assessment and Testing (EMWAT). Proceeding of SETACEurope/OECD/EC Expert Workshop: Veldhoven, The Netherlands, SETAC-Europe, Amsterdam; 1997.

15. Ackermann GE, Schwaiger J, Negele RD, Fent K. Effects of long- 
term nonylphenol exposure on gonadal development and biomarkers of estrogenicity in juvenile rainbow trout Oncorhynchus mykiss. Aquat Toxicol 2002;60:203-21.

16. Okai Y, Sato EF, Higashi-Okai K, Inoue M. Enhancing Effect of the Endocrine Disruptor para-Nonylphenol on the Generation of Reactive Oxygen Species in Human Blood Neutrophils. Environ Health Perspect 2004;112:553-6.

17. Berg AH, Westerlund L, Olsson PE. Regulation of Arctic char (Salvelinus alpinus) egg shell proteins and vitellogenin during reproduction and in response to 17beta-estradiol and cortisol. Gen Comp Endocrinol 2004;135:276-85.

18. Tyler CR, Pottinger TG, Santos E, Sumpter JP, Price SA, Brooks S, et al. Mechanisms controlling egg size and number in the rainbow trout, Oncorhynchus mykiss. Biol Reprod 1996;54:8-15.

19. Fujita T, Fukada H, Shimizu M, Hiramatsu N, Hara A. Quantification of serum levels of precursors to vitelline envelope proteins (choriogenins) and vitellogenin in estrogen treated masu salmon, Oncorhynchus masou. Gen Comp Endocrinol 2004;136:49-57.

20. Anderson MJ, Cacela D, Beltman D, Teh SJ, Okihiro MS, Hinton DE, et al. Biochemical and toxicopathic biomarkers assessed in smallmouth bass recovered from a polychlorinated biphenyl-contaminated river. Biomarkers 2003;8:371-93.

21. Volz DC, Chandler GT. An enzyme-linked immunosorbent assay for lipovitellin quantification in copepods: a screening tool for endocrine toxicity. Environ Toxicol Chem 2004;23:298-305.

22. Martin-Diaz ML, Bambe, S, Casado-Martine C, Sale D, DelValls TA. Toxicokinetics of heavy metals from a mining spill using Carcinus maenas. Mar Environ Res 2004;58:833-7.

23. Cuisset B, Pradelles P, Kime DE, Kuehn ER, Babin P, Davail S, et al. Enzyme immunoassay for 11-ketotestosterone using acetylcholinesterase as label: Application to the measurement of 11-ketotestosterone in plasma of Siberian sturgeon. Comparative Biochemistry and Physiology C Pharmacology. Toxicol Endocrinol 1994;108:229-41.

24. Craft JA, Brown M, Dempsey K, Francey J, Kirby MF, Scott AP, et al. Kinetics of vitellogenin protein and mRNA induction and depuration in fish following laboratory and environmental exposure to oestrogens. Mar Environ Res 2004;58:419-23.

25. Versonnen BJ, Arijs K, Verslycke T, Lema W, Janssen CR. In vitro and in vivo estrogenicity and toxicity of o-, $\mathrm{m}$-, and p-dichlorobenzene. Environ Toxicol Chem 2003;22:329-35.

\section{ANNOUNCEMENT}

\section{$\mathrm{ICOH} 2006$}

The next world congress of $\mathrm{ICOH}$ will be organized in June 2006 in Milan, Italy. It will also celebrate the 100th anniversary and the centennial jubileum of $\mathrm{ICOH}$. The dates of $\mathrm{ICOH} 2006$ have been scheduled for 11th - 16th June, 2006.

Web: http://www.icoh2006.it. / www.icoh.org.sg 